\title{
ESCLARECIMENTO SOBRE CURSOS SUPERIORES A ALUNOS FINALISTAS DO ENSINO MEDIO POR DEPOIMENTOS EM VIDEOS
}

\author{
CLARIFICATION ON UPPER-LEVEL COURSES TO HIGH SCHOOL FINALIST \\ STUDENTS BY TESTIMONIALS IN VIDEOS
}

\author{
ACLARACIONES SOBRE CURSOS SUPERIORES A ALUMNOS FINALISTAS \\ DE LA ESCUELA SECUNDÁRIA POR DESPUENTOS EN VÍDEOS
}

\author{
Christyan Lemos Bergamaschi* \\ christyanlb_27@hotmail.com \\ Juliana Santos Ferreira** \\ julianasantos.92@hotmail.com \\ Maria do Carmo Pimentel Batitucci*** \\ docarmo_batitucci@yahoo.com.br
}

\begin{abstract}
REVISTA PEDAGÓGICA
Revista do Programa de Pós-graduação em Educação da Unochapecó | ISSN 1984-1566

Universidade Comunitária da Região de Chapecó | Chapecó-SC, Brasil Como referenciar este artigo: BERGAMASCHI, C. L; FERREIRA, J. S.; BATITUCCI, M. C. P. Esclarecimento sobre cursos superiores a alunos finalistas do Ensino Médio por depoimentos em vídeos. Revista Pedagógica, Chapecó, v. 19, n. 41, p. 287-301, maio./ago. DOI: http://dx.doi.org/10.22196/rp.v19i41.3641
\end{abstract}

\begin{abstract}
RESUMO: O presente trabalho tem o objetivo de fornecer maiores informações para o entendimento e a divulgação de cursos superiores, através de um estudo exploratório com os estudantes finalistas dos terceiros anos de uma escola pública de Vitória/ES. Buscando investigar aspectos relevantes para a decisão dos alunos, realizamos uma sessão de 20 vídeos com depoimentos de estudantes da graduação, além de questionários para compreender se esta dinâmica ajudou no esclarecimento dos cursos superiores. Com auxílio dos questionários, os alunos foram separados em três grupos: grupo 1, de alunos que escolheram o curso, o qual possuía depoimento no vídeo (32,4\%); grupo 2, de alunos que escolheram o curso, mas não possuía depoimento no vídeo (43,7\%); e grupo 3, de alunos que não tinham decidido qual curso fariam ou não queriam seguir seus estudos no Ensino Superior (23,9\%). Mais da metade dos alunos $(60 \%)$ responderam que os vídeos contribuíram para a decisão de qual curso superior seguir.
\end{abstract}

Palavras-chave: Orientação profissional. Ensino superior. Escolha.

ABSTRACT: The present work has the objective of providing more information for the understanding and dissemination of higher courses, through an exploratory study with finalist students of the third years of a public school of Vitória/ES. Looking to investigate relevant aspects to the students decision, we held a session of 20 videos with testimonials from undergraduate students, as well as questionnaires to understand if this dynamic helped to clarify higher courses. With the help of the questionnaires, students were separated into three groups: group 1, students who chose the course and had testimony in the video $(32,4 \%)$; group 2 , students who chose the course, but did not have video testimony (43,7\%); group 3, students who had not decided which course they would do or did not want to pursue their studies in Higher Education (23,9\%). More than half of the students answered that the videos contributed to the decision of which higher course to follow.

Keywords: Professional Orientation. Higher Education. Choice.

RESUMÉN: Este documento tiene por objeto proporcionar más información para la comprensión y la difusión de la educación superior a través de un estudio exploratorio con estudiantes graduados de tercer curso de una escuela pública de Vitória/ES. Tratando de investigar los aspectos relevantes a la decisión de los estudiantes, se realizó una sesión de 20 vídeos con testimonios de estudiantes graduados, así como cuestionarios para entender si esta dinámica ayudó a clarificar las titulaciones. Con la ayuda de cuestionarios, los estudiantes fueron separados en tres grupos: grupo 1 , los estudiantes que ya habían elegido el curso y que tenían esta declaración en el vídeo $(32,4 \%)$; grupo 2 , los estudiantes que ya habían elegido el curso, pero no apareció en el testimonio de vídeo (43,7\%); y el grupo 3 , los estudiantes que no habían decidido qué curso harían o no querían seguir sus estudios en la Educación Superior $(23,9 \%)$. Más de la mitad de los estudiantes (60\%) respondió que los videos contribuyeron a la decisión de los cuales la universidad a seguir.

Palabras clave: La Orientación Profesional. Educación Superior. Elección. 
* Licenciado em Ciências Biológicas pela Universidade Federal do Espírito Santo (UFES).

** Mestranda em Biologia Animal e Bacharela em Ciências Biológicas pela Universidade Federal do Espírito Santo (UFES).

*** Doutora em Ciências Fisiológicas pela Universidade Federal do Espírito Santo (UFES) e coordenadora de área do Programa Institucional de Bolsas de Iniciação à Docência (PIBID).

\section{INTRODUÇÃO}

Uma das transições marcantes que ocorrem na adolescência é o início da busca por uma escolha profissional. Neste período da vida do jovem, ocorre o término do seu percurso no Ensino Médio e se intensifica a sua busca por uma carreira - pois é o momento de ingresso na faculdade e/ou no mercado de trabalho e gera a necessidade de escolha de um curso superior ou de uma profissão (SANTOS, 2005; SPARTA; GOMES, 2005). Apesar da variedade de possibilidades para continuação dos estudos existente no país, verifica-se uma tendência do jovem que termina o Ensino Médio de fazer escolhas profissionais ligadas aos cursos mais tradicionais oferecidos pela educação superior (SPARTA; GOMES, 2005), normalmente por falta de conhecimento acerca de outros cursos ou, então, pela trajetória histórica destes cursos tradicionais (BARRETO; AIELLO-VAISBERG, 2007).

As perdas de estudantes que iniciam, mas não terminam seus cursos, são desperdícios sociais, acadêmicos e econômicos. No setor público, são recursos investidos sem o devido retorno; no setor privado, é uma importante perda de receitas. Em ambos os casos, a evasão é uma fonte de ociosidade de professores, funcionários, equipamentos e espaço físico (SILVA-FILHO et al., 2007). Dantas et al. (2014) e Diogo et al. (2016) perceberam que as principais causas da evasão são as ideias equivocadas dos alunos sobre a formação, falta de clareza dos campos de atuação e mercado de trabalho, confusão entre cursos com grades curriculares semelhantes, incompatibilidade vocacional, além de disciplinas com alto grau de complexidade, comparado ao Ensino Médio, gerando ansiedade e forte sensação de inaptidão, e ainda Bardagi, Lassance e Paradiso (2003) e Bardagi e Hutz (2009) identificaram que as escolhas iniciais destes alunos têm sido frágeis, pautadas em pouca atividade exploratória, em estereótipos das profissões e respectivas carreiras. De uma forma geral, os participantes consideravam reduzida a quantidade de informações que possuíam, além de inconsistente e, dessa forma, sugeriram que os processos de orientação no final do Ensino Médio poderiam melhorar as decisões tomadas inicialmente, se focalizarem informações sobre profissões e currículos (BARDAGI; HUTZ, 2009). Dos dez cursos listados por estes autores com maior taxa de evasão, três estão no presente estudo: Educação Física, Administração e Jornalismo.

A maioria das pessoas pode realizar escolhas de carreira conhecendo muito pouco sobre as implicações de suas tarefas, dificuldades e responsabilidades. Não existe uma preocupação sistemática da escola ou da família em ensinar os filhos ou alunos, habilidades de tomada de decisão (BARDAGI; LASSANCE; PARADISO, 2003). Verifica-se, em todo o mundo, que a taxa de evasão no primeiro ano de curso é de duas a três vezes maior do que a dos anos 
seguintes (SILVA-FILHO et al., 2007). Contudo, são raríssimas as Instituições de Ensino Superior (IES) brasileiras que possuem um programa institucional profissionalizado de combate à evasão, com planejamento de ações, acompanhamento de resultados e coleta de experiências bem-sucedidas, o que pode ter contribuído para uma evasão anual média de 22\%, entre 2000 e 2005, para o conjunto formado por todas as IES do Brasil (SILVA-FILHO et al., 2007).

A falta de informações precisas sobre os cursos superiores, de uma orientação profissional e a pressão imposta aos estudantes são uns dos fatores responsáveis por uma escolha precipitada de curso. Hoje é fundamental acompanharmos o avanço da liberdade individual de escolha (BARRETO; AIELLO-VAISBERG, 2007) e Bardagi e Hutz (2009) recomendam como intervenções, em maioria absoluta, o auxílio à primeira escolha. Um processo de atendimento à população universitária deve abordar aspectos gerais e específicos de informação, incluindo uma discussão sobre estes fatores externos: mercado, remuneração, perspectivas de inserção profissional, entre outros (LISBOA, 2000).

Considerando o acesso às informações sobre cursos e carreiras, uma premissa para o sucesso de qualquer estratégia de informação é o uso de uma linguagem acessível e aceita pelos jovens. Nesse contexto, a linguagem materializada em diversos gêneros discursivos e a apropriação desses gêneros como forma de inserção social, a introdução a um universo cultural específico pode ser dificultada pelo distanciamento entre o discurso científico e o discurso cotidiano dos estudantes, sendo necessário introduzir novos conhecimentos com um modo narrativo de pensar, próprio dos estudantes (GARCIA, 2009). Uma possibilidade de aproximação entre o discurso científico e o cotidiano do jovem é a utilização de mídias como vídeos, internet e demais tecnologias de informação disponíveis. Ferrés (1994) utiliza o vídeo como processo aliado ao trabalho colaborativo à educação e como instrumento motivador da aprendizagem, gerando dinâmicas participativas e possibilitando a comunicação horizontal (PRATS; PINA, 1991), em uma tentativa de ir ao encontro de necessidades/ desejos dos alunos (ALMEIDA, 2013).

Nesse contexto, o presente trabalho tem como objetivos identificar se os alunos finalistas possuem interesse em ingressar no Ensino Superior, se já possuem a escolha do curso superior e a contribuição do vídeo para a decisão dos discentes.

\section{MATERIAIS E MÉTODOS}

\subsection{Voluntários e confecção dos vídeos}

Selecionamos voluntários, em sua maioria, estudantes finalistas de instituições públicas e privadas, ou profissionais recém-formados, que apresentavam desenvoltura 
para transmitir as informações sobre os seus cursos, por meio da gravação de um vídeo. Ao todo, foram 20 cursos superiores relatados em vídeos, com duração média de cinco minutos cada. Os cursos abordados foram: Administração, Arquitetura e Urbanismo, Artes Visuais, Biblioteconomia, Ciências Biológicas, Cinema de Animação/Artes Digitais, Comunicação Social - Jornalismo, Direito, Educação Física, Engenharia Ambiental, Engenharia de Produção, Fisioterapia, Fonoaudiologia, Geografia, História, Nutrição, Oceanografia, Psicologia, Química e Terapia Ocupacional. A escolha dos cursos para os depoimentos foi pautada pela disponibilidade de voluntários e pela possibilidade de escolha de cursos menos divulgados.

Fizemos uma reunião com cada voluntário para que eles ficassem cientes da pesquisa e de seus objetivos e pudessem assim assinar o Termo de Consentimento Livre e Esclarecido. Além disso, entregamos a cada um deles um roteiro semiestruturado (Anexo I), no qual foram explicados os tópicos envolvidos na confecção do vídeo e esclarecidas as eventuais dúvidas.

Os voluntários gravaram o vídeo e o enviaram posteriormente à equipe do trabalho, para que os vídeos pudessem ser editados, adequando-se assim ao tempo proposto e, também, para que fosse feita a inclusão das legendas.

\subsection{Participantes}

O estudo foi realizado com alunos dos terceiros anos de uma escola pública estadual de Vitória/ES, totalizando 86 alunos. Foram realizados três encontros com os alunos para a devida explicação do projeto e da dinâmica envolvida nos questionários e vídeos. No primeiro encontro, apresentamos a proposta do trabalho e perguntamos se eles estavam dispostos a participar anonimamente; além disso, entregamos os questionários pré-vídeo. No segundo encontro, foram apresentados os vídeos dos cursos; no terceiro, a entrega dos questionários pós-vídeo.

\subsection{Instrumento}

Utilizamos dois questionários para realização da pesquisa com os alunos, um aplicado antes dos vídeos (questionário pré-vídeo) e outro aplicado após a apresentação dos vídeos (questionário pós-vídeo).

\subsubsection{Questionário pré-vídeo}

O questionário pré-vídeo (Anexo II) foi aplicado antes de os alunos assistirem aos vídeos, para sabermos qual era a perspectiva acadêmica/profissional de cada aluno após o ensino médio, ingressar ou não no Ensino Superior.

\subsubsection{Questionário pós-vídeo}

Após a apresentação dos vídeos, aplicamos o questionário pós-vídeo para avaliar se haviam contribuído para o 
esclarecimento de dúvidas sobre os cursos, para uma definição de escolha profissional, e, também, se haviam cursos desconhecidos, além de questões livres para os alunos exporem o que achassem necessário.

Para a aplicação desse questionário, os alunos foram separados em três grupos, em que cada grupo de alunos tinha um modelo de questionário diferente, os quais foram compostos de: 1) alunos que escolheram o curso e que possuía depoimento no vídeo (Anexo III); 2) alunos que escolheram o curso, mas não possuía depoimento no vídeo (Anexo IV); 3) alunos que não tinham decidido qual curso ou não querem seguir seus estudos no Ensino Superior (Anexo V). Todos os questionários continham algumas perguntas em comum para a caracterização do sujeito, assim como uma lista dos 20 cursos apresentados, para que os alunos assinalassem caso não os conhecessem.

\section{RESULTADOS E DISCUSSÃO}

\subsection{Questionário pré-vídeo}

O questionário pré-vídeo foi aplicado a 86 alunos finalistas do Ensino Médio, dos quais 96,5\% decidiram ingressar ao Ensino Superior, e destes, 80,2\% também já haviam escolhido o curso. Os restantes que não optaram pelo curso superior informaram a decisão de realizar um curso técnico. Madeira (2006) observou que os alunos que optam por essa modalidade de ensino pretendem adquirir uma qualificação que facilite uma rápida inserção no mercado de trabalho.

A Tabela 1 mostra o curso escolhido pelos alunos que já tinham tomado sua decisão de prosseguimento de estudos em nível superior.

Podemos notar que o curso mais requerido é o de Direito, seguido de Medicina (FO\% $=15,9$ e 10,1, respectivamente). Dos cursos mencionados pelos alunos, 12 estavam presentes na sessão de vídeos, incluindo Direito.

Acerca de vários dados da literatura a respeito dos obstáculos encontrados na atualidade pelos adolescentes na hora de fazer as primeiras escolhas profissionais e sobre a evasão em cursos superiores (PRIMI et al., 2000; SCHIESSE; SARRIERA, 2000; SPARTA; GOMES, 2005; FARIA; GUZZO, 2007; BARDAGI; HUTZ, 2009; LEHMAN, 2014), constatamos que há uma grande vulnerabilidade das decisões profissionais tomadas na adolescência. E, dentre os principais fatores relacionados às dificuldades de escolha estavam: a imaturidade, a insegurança e a falta de informação. Porém, nossos dados apontam que grande parte dos alunos já havia decidido em qual curso ingressar (80,2\%). Podemos compilar nossos dados com o estudo de Sparta e Gomes (2005), em que grande parte dos alunos de Ensino Médio escolheu como próxima etapa de suas vidas, o vestibular. Esse dado indica que o estudante do Ensino 
292 ESCLARECIMENTO SOBRE CURSOS SUPERIORES A ALUNOS FINALISTAS DO ENSINO MÉDIO POR DEPOIMENTOS EM VÍDEOS

Médio atribui grande importância ao ingresso na educação superior, como se fosse uma etapa obrigatória para se tornarem pessoas mais bem-sucedidas (LASSANCE; GOCKS; FRANCISCO, 1993; SPARTA; GOMES, 2005).

Tabela 1 - Cursos de nível superior pretendidos pelos alunos finalistas do Ensino Médio. [N: número de alunos para determinado curso; FO (\%): frequência de ocorrência do curso] O asterisco indica os cursos que foram apresentados nos vídeos.

\begin{tabular}{|c|c|c|}
\hline Cursos & $\mathbf{N}$ & FO (\%) \\
\hline Administração** & 2 & 2.9 \\
\hline Agronomia & 1 & 1.4 \\
\hline Arquitetura e Urbanismo* & 4 & 5.8 \\
\hline Ciências Biológicas* & 3 & $4 \cdot 3$ \\
\hline Ciências Contábeis & 2 & 2.9 \\
\hline Ciências da Computação & 1 & 1.4 \\
\hline Direito* & 11 & 15.9 \\
\hline Educação Física* & 4 & 5.8 \\
\hline Engenharia & 2 & 2.9 \\
\hline Engenharia Civil & 2 & 2.9 \\
\hline Engenharia Mecânica & 5 & 7.2 \\
\hline Engenharia de Produção* & 1 & 1.4 \\
\hline Engenharia Química & 1 & 1.4 \\
\hline Estética & 1 & 1.4 \\
\hline Filosofia & 1 & 1.4 \\
\hline Fisioterapia* & 1 & 1.4 \\
\hline Fotografia & 1 & 1.4 \\
\hline Geologia & 1 & 1.4 \\
\hline História* & 1 & 1.4 \\
\hline Jornalismo* & 1 & 1.4 \\
\hline Logística & 1 & 1.4 \\
\hline Medicina & 7 & 10.1 \\
\hline Nutrição* & 2 & 2.9 \\
\hline Psicologia* & 4 & 5.8 \\
\hline Publicidade e Propaganda & 1 & 1.4 \\
\hline Química* & 2 & 2.9 \\
\hline Relações Internacionais & 1 & 1.4 \\
\hline Serviço Social & 1 & 1.4 \\
\hline Medicina Veterinária & 4 & 5.8 \\
\hline Total & 69 & 100 \\
\hline
\end{tabular}

Fonte: Dados organizados pelos autores com base na pesquisa realizada.

Apesar da variedade de possibilidades para continuação dos estudos existente no país, verifica-se uma tendência de o jovem que termina o Ensino Médio fazer escolhas profissionais ligadas aos cursos mais tradicionais de graduação oferecidos pelo Ensino Superior (SPARTA; 
GOMES, 2005). Em estudo de Moreira e Faria (2009), verificou-se que grande parte dos alunos de $3^{\circ}$ ano ainda prefere seguir carreiras de maior prestígio social. Cursos como Direito, Farmácia, Engenharia Civil e Administração ocupam 33,5\% dos cursos mais citados. Nossos dados corroboram com a literatura (BORGES; CARNIELLI, 2005; BARRETO; AIELLO-VAISBERG, 2007; MOREIRA; FARIA, 2009), visto que esta cita os cursos de Medicina e/ ou Direito como os principais cursos almejados pelos estudantes. O grande índice de escolha dos cursos mais tradicionais pode estar relacionado com sua ampla divulgação, incluindo o status social e a trajetória histórica destes cursos, além da influência pelos pais (SANTOS, 2005; BARRETO; AIELLO-VAISBERG, 2007).

\subsection{Questionário pós-vídeo}

A aplicação do questionário após a sessão de vídeos envolveu um total de 71 alunos que foram separados em três grupos. O número inferior de alunos quando comparados ao questionário pré-vídeo, se deve ao fato de terem sido aplicados em dias distintos.

A Tabela 2 representa a caracterização dos sujeitos. Podemos notar que os alunos têm uma média de 17 anos de idade, sendo a maioria feminina $(70,5 \%)$. Além disso, $73,5 \%$ dos alunos entrevistados não exercem atividade remunerada, o que pode ter relação com o grande número de alunos que querem prosseguir com os estudos em nível superior (96,5\%), já que estes não teriam maiores responsabilidades além dos estudos. Três alunos, dois do grupo 1 e um do grupo 3, não mencionaram se exercem atividade remunerada, sendo que esse último também não identificou o sexo.

Tabela 2 - Caracterização dos alunos que responderam ao questionário pós-vídeo da dinâmica de sessão de vídeos. (N: número de alunos; Idade: média da idade dos alunos; Masculino e Feminino: número de indivíduos de cada sexo; Remunerado e Não Remunerado: quantidade dos alunos que exerce ou não alguma atividade remunerada).

\begin{tabular}{ccccccc}
\hline & N & Idade & Masculino & Feminino & Remunerado & Não Remunerado \\
\hline Grupo 1 & 23 & 17.04 & 6 & 17 & 5 & 16 \\
Grupo 2 & 31 & 17.03 & 10 & 21 & 6 & 25 \\
Grupo 3 & 17 & 17.35 & 11 & 5 & 7 & 9 \\
Total & 71 & 17.14 & 27 & 43 & 18 & 50 \\
\hline
\end{tabular}

Fonte: Dados organizados pelos autores com base na pesquisa realizada.

A Tabela 3 demonstra a lista de cursos que foram assinaladas pelos alunos caso não conhecessem tais cursos. Notamos que o curso de Terapia Ocupacional foi o menos conhecido, seguido de Oceanografia e Biblioteconomia, mais da metade dos estudantes, do total de 71, desconheciam a existência desses cursos. Os alunos relataram o que desconheciam: "Não sabia que existia faculdade de Biblioteconomia", "Eu não fazia ideia da faculdade de Oceanografia, e pra que ela servia", "Não sabia que Terapia 
Ocupacional exercia aquelas funções tão importantes que às vezes nem nos damos conta". A alta taxa de desconhecimento acerca destes cursos pode estar associada à escassa divulgação destas profissões, e/ou ao fato de serem cursos recentes nas Universidades e Faculdades do Espírito Santo.

Tabela 3 - Quantificação dos cursos desconhecidos pelos alunos.

\begin{tabular}{lcccc}
\hline Cursos Desconhecidos & Grupo 1 & Grupo 2 & Grupo 3 & Total \\
\hline Artes Visuais & 1 & 3 & 3 & 7 \\
Biblioteconomia & 16 & 15 & 10 & 41 \\
Cinema de Animação & 9 & 9 & 2 & 20 \\
Jornalismo & 1 & 1 & 0 & 2 \\
Engenharia Ambiental & 1 & 3 & 0 & 4 \\
Engenharia de Produção & 1 & 6 & 0 & 9 \\
Fisioterapia & 0 & 1 & 2 & 17 \\
Fonoaudiologia & 3 & 12 & 11 & 44 \\
Oceanografia & 14 & 19 & 12 & 46 \\
\hline
\end{tabular}

Fonte: Dados organizados pelos autores com base na pesquisa realizada.

Seguindo para a análise dos questionários individualmente, foram obtidos os seguintes resultados:

No grupo 1, dos alunos que já tinham escolhido o curso e possuía no vídeo, 69,6\% dos alunos responderam que o vídeo contribuiu para reforçar sua decisão em relação ao curso escolhido, e a maioria (87,5\%) diz que isso se deve as informações apresentadas. Notamos que os vídeos apresentaram informações desconhecidas pelos alunos, a principal delas foram as áreas de atuação que aquele profissional está apto a seguir, sendo expresso por 55,6\% dos alunos. Por fim, pedimos aos alunos para escreverem curiosidades relatadas nos vídeos e, neste espaço, 80\% deles citaram os cursos que desconheciam. Um aluno, cuja escolha do curso foi Oceanografia, respondeu que ajudou e o que o vídeo mostrou serviu para reforçar sua decisão: "Sim, a ampla variedade que eu posso exercer caso consiga seguir a minha escolha".

No grupo 2, mesmo no caso de alunos que escolheram o curso e não estavam presentes na sessão, $71 \%$ dos alunos disseram que os vídeos contribuíram para reafirmarem sua posição quanto à escolha profissional. E isso pode ter ocorrido devido à comparação de cursos relacionados ou não ao da sua escolha. Esclarecendo, assim, dúvidas pendentes, comparações para que o aluno possa reafirmar sua decisão inicial. Finalizando o questionário, os grupos 1 e 2 mostraram como curiosidades, as áreas de atuação e a variedade de cursos desconhecidos. Um aluno que escolheu Medicina como opção de curso, respondeu que tinha alguma curiosidade no vídeo: "Sim. Como, por exemplo, a Terapia Ocupacional, que eu não sabia como funcionava. Achava que era igual Terapia mesmo [...]". 
No grupo 3, estão os alunos que não queriam ou não decidiram pelo curso superior. Um dos alunos respondeu: "Não me vejo apto a cursar o Ensino Superior", talvez por falta de informação a respeito do ingresso no ensino superior ou por duvidar de sua capacidade. Aqueles que mudaram de ideia e tomaram uma decisão após assistirem ao vídeo, relataram que isso se deve à possibilidade de comparação com outros cursos. Deste grupo, dois alunos relataram que tomaram a decisão de ingressar no curso de Engenharia após assistirem aos vídeos. A maioria daqueles que responderam que os vídeos não contribuíram para uma tomada de decisão, explicaram que o curso de sua pretensão não constava dentre aqueles trabalhados nos vídeos, o que mostra que esses alunos interpretaram de forma equivocada a qual grupo pertenciam, eles estariam encaixados no grupo 2. Neste grupo, 53,3\% dos alunos relataram conhecer as informações dos vídeos apresentados, e aqueles que desconheciam apontaram os cursos que não conheciam (Tabela 3).

As escolas precisam reforçar as formas de acesso ao Ensino Superior, a importância do Exame Nacional do Ensino Médio (ENEM) nos dias atuais, os requisitos para serem contemplados em programas de bolsas disponíveis, datas de inscrições e demais informações acerca do assunto. Em uma proposta de orientação profissional realizada por Dantas et al. (2014), também foi destacada a carência das instituições escolares em trabalhar essas informações a fim de favorecer e despertar uma identidade profissional. A escolha profissional tem sido objeto de estudo e análises de muitos autores, e várias propostas já foram formuladas, visando a facilitar este processo (BOHOSLAVSKY, 1998; NEIVA, 2002; GIACAGLIA, 2003). Entretanto, ainda são poucos os jovens que elaboram esta decisão de forma consciente e madura e muitos acabam abandonando seus projetos profissionais (NEIVA et al., 2005). Uma análise dos relatórios de exames vestibulares da Universidade Federal do Rio Grande do Sul (UFRGS) e da Universidade Federal de Santa Catarina (UFSC) no início da década de 1990 mostrou que cerca de 30\% dos vestibulandos afirmaram já ter prestado vestibular para outro curso anteriormente (LUCCHIARI, 1992). Apenas $5 \%$ dos jovens que ingressam em um curso superior tiveram certeza de sua escolha (AVANCINI, 1998).

Se, antigamente, tínhamos algumas dezenas de profissões possíveis entre aquelas que exigiam cursos de nível médio e superior, hoje há um aumento significativo de profissões no mercado devido às rápidas transformações globais, que demandam novas escolhas e oferecem novas possibilidades; porém, causa mais dúvida diante de tantas opções (BARRETO; AIELLO-VAISBERG, 2007, CONSTANTINO, 2013).

As orientações sobre o futuro acadêmico/profissional para os alunos são imprescindíveis, importantes para guiá-los em suas decisões. Uma forma tradicional de 
divulgação de cursos superiores é a feira/mostra de cursos, que funciona com estudantes ou profissionais de cada curso que ficam em tendas para sanar dúvidas aos interessados visitantes; no entanto, demanda a reunião dessas pessoas aptas a falar sobre o curso, todas juntas em um mesmo lugar e com horário estabelecido, além da visita dos alunos ao local, o que podem ser complicadores ao preparar a divulgação nesse formato.

Uma alternativa diferente de divulgação seria a aplicação de testes vocacionais, assim como realizado por Domingues, Lemos e Walter (2005), em que foi trabalhado em dois momentos: primeiramente, com o teste visual de interesses, supervisionando a apuração dos resultados de cada aluno; em segundo lugar, a interpretação dos resultados feita por uma profissional e apresentação final aos alunos. As oficinas de orientação profissional também são importantes meios de divulgação, como mostrado no estudo de Dantas et al. (2014); entretanto, o fator tempo e a mobilização de profissionais na escola para orientação ainda foram necessários para realizar tanto os testes quanto as oficinas.

A possibilidade de apresentar os cursos em formato de vídeos acelera o tempo de acesso às informações necessárias para esclarecer eventuais dúvidas, com respostas a perguntas frequentes dos alunos, o que, muitas vezes por falta de conhecimento do que é necessário saber para o futuro profissional, não seria perguntado caso a divulgação fosse feita em tendas, por meio de testes vocacionais ou oficinas. Além disso, não há necessidade de os estudantes ou profissionais de cada curso estarem presentes para esclarecer as dúvidas, podendo ser trabalhado a qualquer momento em que a escola julgar pertinente. A ausência destas oportunidades ao longo do desenvolvimento vocacional, principalmente na adolescência, pode resultar em imaturidade e insegurança nos jovens e adultos em períodos posteriores da vida profissional, muitas vezes incapacitando-os para a formulação de projetos profissionais consistentes (BARDAGI; LASSANCE; PARADISO, 2003). As escolhas profissionais, teoricamente, determinam a satisfação pessoal, requisito para competência profissional, para colocação de profissionais espontâneos e criativos no mercado, colaborando para o bem-estar social e desenvolvimento socioeconômico, além de minimizar os gastos públicos no que se refere à vaga ociosa e evasão universitária (CONSTANTINO, 2013). Portanto, a orientação profissional é de suma importância aos estudantes, independentemente de qual for o método utilizado para a sua realização.

Neste estudo, aproximadamente $60 \%$ dos alunos responderam que os vídeos contribuíram para a decisão, que reforçaram ou ajudaram na escolha do curso superior, sendo relatados que as informações contidas nos vídeos e a linguagem utilizada foram os fatores determinantes para um melhor esclarecimento sobre o curso. Walsh e Savickas (2005) propõem que o futuro das escolhas vocacionais 
depende da capacidade de os orientadores responderem às mudanças na sociedade, ao oferecer modelos, métodos e materiais que permitam uma intervenção adaptada ao contexto atual. Nossa proposta diante do esclarecimento de cursos superiores foi trazer uma aproximação no discurso da divulgação, proporcionando uma comunicação horizontal (PRATS; PINA, 1991) com os alunos. Dessa forma, a utilização do vídeo gravado por estudantes do Ensino $\mathrm{Su}-$ perior aproxima a sala de aula do cotidiano, das linguagens de aprendizagem e comunicação da sociedade urbana, e também introduz novas questões no processo educacional (MORÁN, 1995).

\section{CONSIDERAÇÕES FINAIS}

Nota-se que os jovens têm grande anseio pela independência e profissionalização, para cada vez tornar-se melhor e ser capaz de enfrentar a competitividade crescente do mercado de trabalho (AZEVEDO; FARIA, 2001). Porém, segundo esses autores, muitas vezes, os motivos que levam os alunos a escolherem determinado curso como carreiras não são acompanhados por profissionais especializados (como um psicólogo ou psicopedagogo) e os fazem tomar decisões precipitadas, optando por cursos que lhe forneçam mais possibilidades e variabilidade de emprego ou que sejam de mais fácil acesso e que lhe exijam menor esforço para sua realização. Um ambiente formador ainda no Ensino Médio pode contribuir muito para a ampliação da visão dos estudantes sobre as profissões (MOREIRA; FARIA, 2009). Compreende-se que cada vez mais é preciso oferecer aos alunos do Ensino Médio uma orientação vocacional e esclarecimentos sobre o papel do Ensino Superior e a relação com a escolha da profissão. Para isso, podemos nos aliar a diferentes modos de divulgação de cursos, como depoimento de estudantes de graduação. Dessa forma, estabelecemos uma empatia com os alunos, que trazem em suas bagagens outras linguagens e formas de expressão que precisam ser reveladas e trabalhadas.

Apesar de ser geralmente associada ao lazer e entretenimento, a produção de vídeos digitais pode ser utilizada como atividade de ensino e aprendizagem com vasto potencial educacional ainda a ser explorado (VARGAS, ROCHA; FREIRE, 2007). Dentre os usuários mais interessados nesse tipo de atividade, estão crianças e adolescentes - um público que crescentemente se identifica muito com esse tipo de mídia devido ao seu caráter altamente motivacional como indicam os estudos de Shewbridge e Berge (2004) e Ellis, Lee e Tham (2004).

A confecção dos vídeos sobre os cursos superiores abre possibilidades para projetos futuros, como inserir vídeos dos cursos superiores em uma plataforma digital (blog, site, rede social etc.), para que os interessados abrissem apenas o vídeo do curso de sua preferência, facilitando não somente o esclarecimento sobre o curso de interesse 
como também a busca por informações. Este meio facilitará o desejo de pesquisa nos alunos para aprofundar o assunto (MORÁN, 1995).

\section{REFERÊNCIAS}

ALMEIDA, Barbara Cristina de Oliveira. Aprendizagem cooperativa e colaborativa recorrendo ao vídeo: uma abordagem no contexto do ensino profissional. Relatório de Estágio. Mestrado em Ensino de Informática. Universidade do Minho, 2013.

AVANCINI, Marta. Evasão em universidade pública chega a 40\%. Folha de São Paulo, Caderno Cotidiano, v. 1,maio, 1998. (s/n).

AZEVEDO, Ângela Sá; FARIA, Luísa. Motivação, sucesso e transição para o ensino superior. Psicologia, v. 20, n. 2, p. 69-93, 2001.

BARDAGI, Marúcia Patta; HUTZ, Cláudio Simon. "Não havia outra saída": percepções de alunos evadidos sobre o abandono do curso superior. Psico-USF, v. 14, n. 1, p. 95105, jan./abr. 2009.

BARDAGI, Marúcia Patta; LASSANCE, Maria Célia Pacheco; PARADISO, Ângela Carina. Trajetória Acadêmica e Satisfação com a Escolha Profissional de Universitários em Meio de Curso. Revista Brasileira de Orientação Profissional, v. 4, n. 2, p. 153-166, 2003.

BARRETO, Maria Auxiliadora; AIELLO-VAISBERG, Tania. Escolha profissional e dramática do viver adolescente. Psicologia \& Sociedade, v. 9, n. 1, p. 107-114, jan./abr. 2007.

BOHOSLAVSKY, Rodolfo. Orientação vocacional: a estratégia clínica. Tradução de José Maria Valeije Bojart. 11. ed. São Paulo: Editora Martins Fontes, 2003.

BORGES, José Leopoldino das Graças; CARNIELLI, Beatrice Laura. Educação e estratificação social no acesso à universidade pública. Cadernos de Pesquisa, v. 35, n . 124, p. 113-139, jan./abr. 2005.

CONSTANTINO, Graciela. Teoria e prática em orientação profissional em tempos de globalização. Revista da Faculdade de Educação, v. 20, ano 11, n. 2, p. 69-79, jul./dez. 2013.

DANTAS, Danielle Santiago Câmara; NASCIMENTO, Emilly da Silva; MONTEIRO, Laísa Ravena Soares Gonçalves; OLIVEIRA, Diego Ferreira; SOBRINHO, Edinéia Pereira. Oficina de orientação profissional para 
estudantes de escola pública: um relato de experiência. Revista Extendere, v. 2, n. 1, p. 177-188, jan./jul. 2014.

DIOGO, Maria Fernanda; RAYMUNDO, Luana dos Santos; WILHELM, F.A.; ANDRADE, Sílvia Patricia Cavalheiro; LORENZO, Flora Moura; ROST, Flávia Trento; BARDAGI, Marúcia Patta. Percepções de coordenadores de curso superior sobre evasão, reprovações e estratégias preventivas. Avaliação, Campinas; Sorocaba, v. 21, n. 1, p. 125-151, mar. 2016.

DOMINGUES, Maria José Carvalho de Souza; LEMOS, Roselie de Faria; WALTER, Silvana Anita. Novas estratégias para divulgação de cursos de graduação: um relato da aplicação do projeto "Seu aluno bem orientado". In: Colóquio Internacional sobre Gestión Universitaria en América del Sur: Poder, Gobierno y Estratégias em las Universidades de America del Sur, 5., diciembre 2005, Mar del Plata. Anais... Mar del Plata: Universidad Nacional de Mar del Plata, diciembre 2005. (s/n).

ELLIS, Glenn; LEE, Suh. Kathryn; THAM, Alyssa. Learning Engineering Mechanics Through Video Production. In: 34TH ASEE/IEEE FRONTIERS IN EDUCATION CONFERENCE, Savannah, GA, 2004. Anais... Savannah State University, 2004. p. 20-23.

FARIA, Luiz Roberto Paiva; GUZZO, Raquel Souza Lobo. Em tempo de globalização: a representação social de emprego, trabalho e profissão em adolescentes. Estudos e Pesquisas em Psicologia, Rio de Janeiro, v. 7, n. 3, p. 387-404, dez. 2007.

FERRÉS, Joán. Vídeo y Educación. Barcelona: Ediciones Paidós Ibérica, 1994.

GARCIA, Junia Freguglia Machado. A produção de sentidos no contexto de uma aula de ciências sobre adaptação biológica mediada por um desenho de animação. 2009. 108 f. Dissertação (Mestrado em Educação) - Programa de Pós-graduação em Educação, Universidade Federal de Minas Gerais, Belo Horizonte, 2009.

GIACAGLIA, Lia Renata Angelini. Orientação Vocacional por atividades: uma nova teoria e uma nova prática. São Paulo: Pioneira Thomson Learning, 2003.

LASSANCE, Maria Célia; GOCKS, Anelise; FRANCISCO, Deise Juliana. Escolha profissional em universitários: Estilo de escolha. In: ASSOCIAÇÃO BRASILEIRA DE ORIENTADORES PROFISSIONAIS (Org.). I Simpósio Brasileiro de Orientação Vocacional e Ocupacional. São Paulo: ABOP, 1993. (s/p). 
LEHMAN, Yvette Piha. University students in crisis: University dropout and professionalre-selection. Estudos de Psicologia, Campinas, n. 31, v. 1, p. 45-53, jan./mar. 2014.

LISBOA, Marilu Diez. A formação de orientadores profissionais: um compromisso social multiplicador. In: LISBOA, Marilu Diez; SOARES, Dulce Helena Penna (Org.). Orientação profissional em ação: Formação e prática de orientadores. São Paulo: Summus, 2000. p. 11-23.

LUCCHIARI, Dulce Helena Penna Soares. O que é orientação profissional? Uma nova proposta de atuação. In: LUCCHIARI, Dulce Helena Penna Soares (Org.). Pensando e vivendo a orientação profissional. São Paulo: Summus, 1992. p. 11-16.

MADEIRA, Maria Helena. Ensino profissional de jovens: um percurso escolar diferente para a (re)construção de projectos de vida. Revista Lusófona de Educação, v. 7, p. 121-141, 2006.

MORÁN, José. O vídeo na sala de aula. Revista Comunicação e Educação. São Paulo, v.2, p. 27-35, jan./abr. 1995 .

MOREIRA, Sergio Antonio Lobo; FARIA, Juliana Guimarães. Fatores que atuam na escolha do curso de graduação de alunos do $3^{\circ}$ ano do ensino médio de escolas de Anápolis, GO. In: SIMPÓSIO DE ESTUDOS E PESQUISAS DA FACULDADE DE EDUCAÇÃO DA UFG, 18., 2009, Goiânia. Anais... Goiânia: UFG, 2009. (s/n).

NEIVA, Kathia Maria Costa. Entendendo a Orientação Profissional. 2. ed. São Paulo: Paulus, 2002.

NEIVA, Kathia Maria Costa; SILVA, Mariita Bertassoni; MIRANDA, Vera Regina; ESTEVES, Cristiano. Maturidade e escolha profissional no ensino médio. Revista Brasileira de Orientação Profissional, v. 6, n. 1, p. 1-14, 2005.

PRATS, Joan; PINA, Antonio. El Vídeo, ensenar vídeo, ensenarconel vídeo. Barcelona: Ediciones G. Gili. 1991.

PRIMI, Ricardo; MUNHOZ, Alícia Maria Hernandez; BIGHETTI, Cássia Aparecida; DI NUCCI, Eliane Porto; PELLEGRINI, Maria Carolina K.; MOGGI, Melissa Aparecida. Desenvolvimento de um inventário de levantamento das dificuldades da decisão profissional. Revista Psicologia Reflexão e Crítica, Porto Alegre, v. 13, n. 3, p. 451-463, 2000.

SANTOS, Larissa Medeiros Marinho. O papel da família e dos pares na escolha profissional. Psicologia em Estudo, Maringá, v. 10, n. 1, p. 57-66, jan./abr. 2005. 
SCHIESSE, Claudia; SARRIERA, Jorge Castella. O ingresso à universidade: Dificuldades e expectativas dos jovens em relação à escolha do curso universitário. Psico, v. 31, n. 2, p. 123-146, 2000.

SHEWBRIDGE, William; BERGE, Zane. The role of theory and technology in learning video production: the challenge of change. International Journal on E-Learning, v. 3, n. 1, p. 31-39, jan./mar. 2004.

SILVA-FILHO, Roberto Leal Lobo; MOTEJUNAS, Paulo Roberto; HIPÓLITO, Oscar; LOBO, Maria Beatriz de Carvalho Melo. A evasão no ensino superior brasileiro. Caderno de Pesquisa, v. 37, n. 132, p. 641-659, set./dez. 2007.

SPARTA, Mônica; GOMES, William. Importância atribuída ao ingresso na educação superior por alunos do ensino médio. Revista Brasileira de Orientação Profissional, v. 6, n. 2, p. 45-53, 2005.

VARGAS, Ariel; ROCHA, Heloísa Vieira; FREIRE, Fernanda Maria Pereira. Promídia: produção de vídeos digitais no contexto educacional. CINTED-UFRGS: Novas Tecnologias na Educação, v. 5, n. 2, p. 1-13, dez. 2007.

WALSH, Bruce; SAVICKAS, Mark. Current issues and innovations in vocational psychology. In: WALSH, Bruce; SAVICKAS, Mark (Org.). Handbook of vocational psychology: Theory, research and practice. 3. ed. Hillsdale: Lawrence Erlbaum Associates, 2005. p. 3-11.

Recebido em: 02/04/2017 Aprovado em: 10/07/2017 